\title{
Effect of Zener-Hollomon Parameter on Microstructure and Mechanical Properties of Copper Subjected to Friction Stir Welding
}

\author{
Nan $\mathrm{Xu}^{1} \cdot$ Ruo-Nan Feng ${ }^{1} \cdot$ Wen-Feng Guo ${ }^{1} \cdot$ Qi-Ning Song $^{1} \cdot$ Ye-Feng Bao ${ }^{1}$ \\ Received: 8 May 2019 / Revised: 31 May 2019 / Published online: 16 August 2019 \\ (C) The Chinese Society for Metals (CSM) and Springer-Verlag GmbH Germany, part of Springer Nature 2019
}

\begin{abstract}
In this work, the influence of the Zener-Hollomon $(Z)$ parameter on the microstructure and mechanical properties of copper subjected to friction stir welding (FSW) was investigated. Liquid $\mathrm{N}_{2}$ cooling was conducted to control the cooling rate after the FSW. The obtained results demonstrate that the $Z$ parameter was dependent on the tool rotation rate during the FSW, i.e., a higher tool rotating rate resulted in a lower $Z$ parameter. The grain size in the stir zone decreased with the increase in the $Z$ parameter. The relationship between the yield strength and the $Z$ parameter is established as $\sigma_{0.2}=\sigma_{0}+k Z^{n}$. This relationship exhibited two different plots under the conditions of air cooling and liquid $\mathrm{N}_{2}$ cooling. Even at a similar $Z$ parameter, a significant yield strength difference occurred because massive dislocations, which were caused by the prevention of the post-annealing effect, were maintained in the stir zone. This study suggests that the influence of the post-annealing effect should not be neglected when analyzing the relationship between the $Z$ parameter, microstructure, and mechanical properties.
\end{abstract}

Keywords Copper $\cdot$ Friction stir welding $\cdot$ Microstructure $\cdot$ Mechanical properties

\section{Introduction}

Welding is an important processing method for expanding the industrial application of copper [1-5]. As the traditional fusion welding method is used for the joining of copper, a large heat input is usually required because the high thermal conductibility of copper results in a coarsened grain structure, and a wide heat-affected zone (HAZ) is produced in the welded joint [2]. Friction stir welding (FSW), which is a solid-state joining technology, can completely solve these problems because the welding process is conducted below the melting point of the materials [6]. The effects of the FSW parameters on the microstructure and mechanical properties of copper joints have been extensively investigated [7-13]. Xie et al. [7] and Liu et al. [8] obtained high-quality FSW copper joints even when using low heat input conditions (i.e., increased welding speed or reduced tool rotating rate)

Available online at http://link.springer.com/journal/40195

$\mathrm{Nan} \mathrm{Xu}$

xunan@hhu.edu.cn; xunan20032389@126.com

1 College of Mechanical and Electrical Engineering, Hohai University, Changzhou 213022, China and found that the microstructure and mechanical properties could be significantly improved. Sun et al. [9] operated the FSW of copper using different axis forces and found that remarkable grain refinement and enhanced mechanical properties were achieved by increasing the axis force. Xue et al. [10] conducted the FSW of copper in water, which resulted in a sound welded joint with a narrowed HAZ. The dislocation density in the HAZ increased, and the mechanical properties of the joint were also improved. In our previous studies, it was found that the post-annealing effect after the FSW significantly affected the microstructures and mechanical properties of welded joints [11-13]. Rapid cooling technology with the use of liquid $\mathrm{N}_{2}$ can eliminate the post-annealing effect and results in the ultrafine grains, which were generated during the stirring stage, remaining in the stir zone (SZ) without experiencing grain coarsening [11]. Thus, the mechanical properties of the welded joints were significantly improved $[12,13]$.

Based on the existing literature, it is evident that the microstructure and mechanical properties of the FSW copper joints are determined by the combined effect of the strain rate, temperature, and cooling rate. The combined influence of the strain rate $(\dot{\varepsilon})$ and deformation temperature $(T)$ is usually defined by the Zener-Hollomon (Z) parameter [14-17], 
Table 1 Tool material and dimensions used in this study

\begin{tabular}{llll}
\hline Material & $\begin{array}{l}\text { Shoulder diam- } \\
\text { eter }(\mathrm{mm})\end{array}$ & $\begin{array}{l}\text { Probe diameter } \\
(\mathrm{mm})\end{array}$ & $\begin{array}{l}\text { Probe length } \\
(\mathrm{mm})\end{array}$ \\
\hline $\begin{array}{l}\text { WC-Co based } \\
\text { steel }\end{array}$ & 12 & 4 & 1.8 \\
\hline
\end{tabular}

Table 2 A summary of the welding conditions for the FSW experiment

\begin{tabular}{llllll}
\hline Label & $\begin{array}{l}\text { Rotation } \\
\text { rate }(\mathrm{rpm})\end{array}$ & $\begin{array}{l}\text { Welding } \\
\text { speed }(\mathrm{mm} / \\
\text { min) }\end{array}$ & Load $(\mathrm{t})$ & $\begin{array}{l}\text { Tilt angle } \\
\left({ }^{\circ}\right)\end{array}$ & $\begin{array}{l}\text { Cooling } \\
\text { media }\end{array}$ \\
\hline $1 \#$ & 600 & & 1.5 & 3 & Air \\
$2 \#$ & 500 & & & & $\begin{array}{l}\text { Air } \\
3 \#\end{array}$ \\
400 & & & Air \\
$4 \#$ & 1000 & 200 & & & Liquid $\mathrm{N}_{2}$ \\
$5 \#$ & 900 & & & Liquid $\mathrm{N}_{2}$ \\
$6 \#$ & 800 & & & Liquid $\mathrm{N}_{2}$ \\
$7 \#$ & 700 & & & Liquid $\mathrm{N}_{2}$ \\
\hline
\end{tabular}

$Z=\dot{\varepsilon} \exp (Q / R T)$,

where $Q$ is the related activation energy for deformation and $R$ is the gas constant. The $Z$ parameter has already been used in predicting the microstructure and mechanical properties of copper subjected to severe plastic deformation, such as rolling and equal-channel angular pressing [18-20]. However, the relationship between the microstructure, mechanical properties, and $Z$ parameter of FSW copper remains unclear. In addition, the cooling rate also plays an important role in the final grain structure via affecting the grain growth just after the FSW. During the post-welding period, grain coarsening usually occurs due to the annealing effect, and it is difficult to understand how the $Z$ parameter affects the actual microstructure and mechanical properties of the SZ. Therefore, in the present study, a rapid cooling FSW (RC-FSW) method was used to reduce the influence of the post-annealing effect, and the relationship between the $Z$ parameter, microstructure, and mechanical properties of FSW copper was investigated.

\section{Experimental}

Two-mm-thick commercial pure copper plates with an annealed condition were used in this study. The tool dimensions and the welding parameters used in this study are listed in Tables 1 and 2, respectively. To prevent the oxidation of the copper, argon protection was used throughout the welding process. The liquid $\mathrm{N}_{2}$ nozzle was set $50 \mathrm{~mm}$ behind the rotating tool, and the welding seam was rapidly cooled during the welding process. The rotation rate with or without liquid $\mathrm{N}_{2}$ cooling was completely different. The $Z$ parameter was very sensitive to the rotation rate. To receive some $\mathrm{Z}$ parameters in a relative wide range, the rotation rates of 400-1000 rpm were selected. However, as the rotation rate increased to $700-1000 \mathrm{rpm}$, the temperature in the SZ was easy to overheat, leading to poor weld formation. Therefore, to receive a good weld appearance, liquid nitrogen was adopted.

The schematic of the RC-FSW process is illustrated in Fig. 1. A K-type thermocouple was placed at the interface of the two plates to record the peak temperatures in the SZ [21]. After FSW, electron backscattered diffraction (EBSD) measurements were carried out using an EDAX TSL OIM ${ }^{\mathrm{TM}}$ system to investigate the grain structure in both the SZ and the base material (BM). The EBSD camera was installed in a field emission scanning electron microscope (FE-SEM), and the scanning step was set as $0.5 \mu \mathrm{m}$ with an accelerating voltage of $20 \mathrm{kV}$. The substructures in the SZs were also characterized via transmission electronic microscopy (TEM). For the TEM sample preparation, thin polished samples were double-jet electro-polished using a solution of $\mathrm{HPO}_{4} / \mathrm{CH}_{4} \mathrm{O} / \mathrm{H}_{2} \mathrm{O}=1: 1: 2$ in volume at $10 \mathrm{~V}$ and $-30{ }^{\circ} \mathrm{C}$. The average Vickers hardness of the SZs and the BM was measured with a load of $100 \mathrm{~g}$ for $15 \mathrm{~s}$. Five points at different locations were measured in the SZ, as shown in Fig. 1. The tensile specimens only contained a SZ with a gauge size of $12^{\mathrm{L}} \mathrm{mm} \times 4^{\mathrm{W}} \mathrm{mm} \times 1.8^{\mathrm{T}} \mathrm{mm}$ and were machined parallel to the welding direction, as shown in Fig. 1. The tensile tests were carried out using an Instron-type testing machine with a crosshead speed of $1 \mathrm{~mm} / \mathrm{min}$.

\section{Results and Discussion}

Figures 2 and 3 show the inverse pole figures and histograms of the misorientation angle distributions of the $\mathrm{BM}$ and the SZs, respectively. In Fig. 3, the misorientation angles of $2 \leq \theta<15^{\circ}, 15 \leq \theta<60^{\circ}$, and $\theta=60^{\circ}$ are regarded as the low-angle grain boundary (LAGB), high-angle grain boundary (HAGB), and twin boundary (TB), respectively. The grains in the BM exhibited an equiaxed shape because the BM was received by cold rolling and the subsequent annealing process, and the average grain size was $28.2 \mu \mathrm{m}$. For the conventional FSW (C-FSW), as shown in Figs. $2 b-d$ and $3 \mathrm{~b}-\mathrm{d}$, the grain size in the $\mathrm{SZ}$ was refined to $11.3-17.5 \mu \mathrm{m}$, and the HAGB ratio was similar to the BM. In particular, the maximum HAGB ratio was located at $60^{\circ}$, which is a result of the TB caused by the post-annealing effect. It was found that the SZs that were produced by C-FSW exhibited a grain structure similar to that of the BM. For RC-FSW, in contrast, the SZs not only exhibited an ultra-refined grain structure (1.7-7.5 $\mu \mathrm{m})$, but also had a higher LAGB ratio than those 


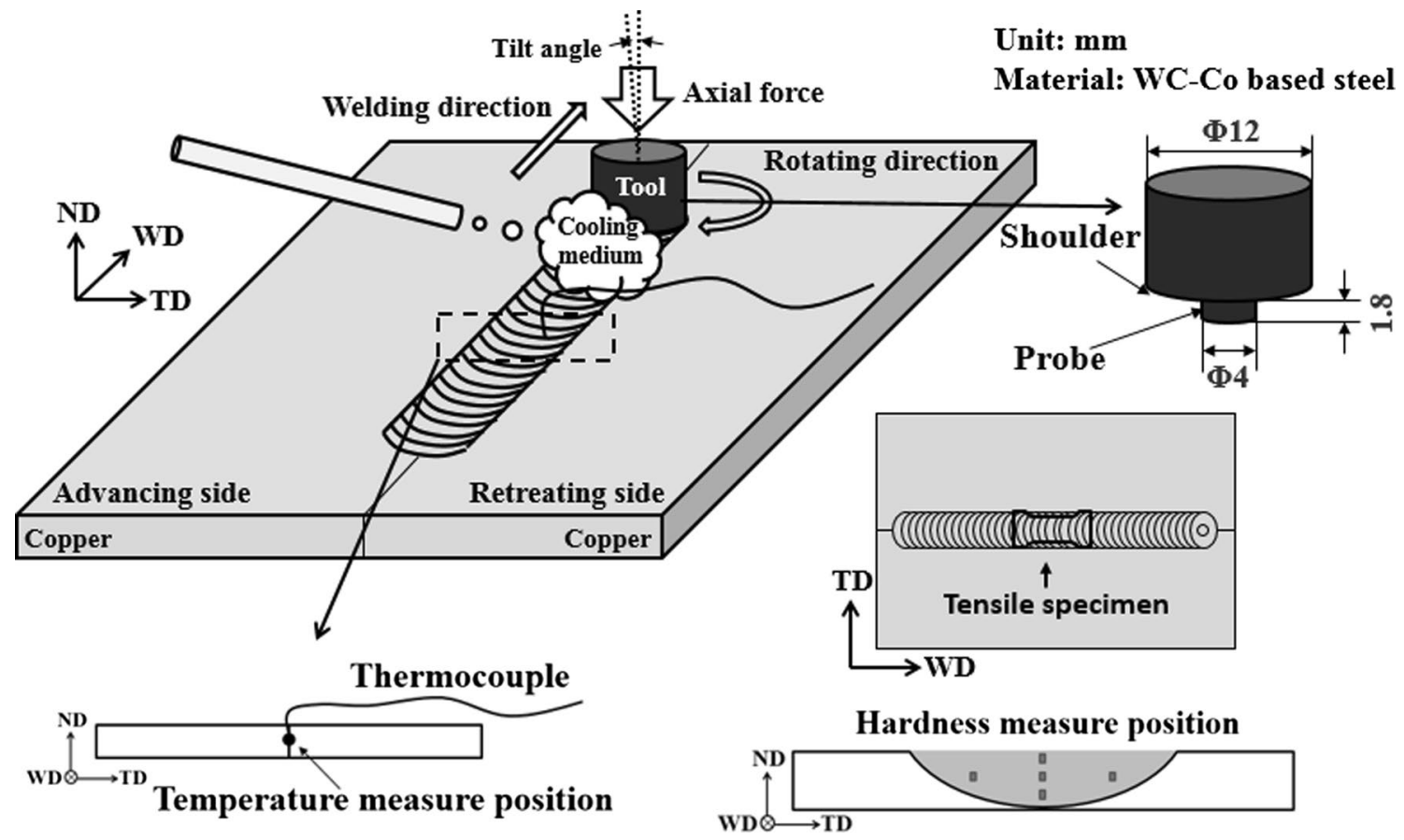

Fig. 1 Schematic of the RC-FSW process and cutting position of the tensile specimen. The welding direction, transverse direction, and platenormal direction are indicated by WD, TD, and ND, respectively

of the BM and C-FSW (Figs. 2e-h and 3e-h). Interestingly, the ratios of the HAGB and TB significantly decreased as the liquid $\mathrm{N}_{2}$ cooling was conducted. It is believed that the LAGB was directly related to the dislocation structure; in the case of liquid $\mathrm{N}_{2}$ cooling, the dislocation, which was induced by serious plastic deformation, disappeared due to the post-annealing effect. It is concluded that the ultrafine grains with a high dislocation density, which were generated around the rotating tool, were maintained in the SZ due to the prevention of the post-annealing effect.

Mechanical properties, including the Vickers hardness and tensile test results of the BM and the SZs, are summarized in Table 3. Generally, both the strength and the hardness in the SZs were higher than those in the BM due to the grain refinement. The SZs obtained by RC-FSW exhibited greater values of hardness, yield strength (YS), and ultimate tensile strength (UTS) than the SZs obtained by C-FSW due to the significant grain refinement and increased dislocation density. Figure 4 shows the bright-field TEM images of the SZs obtained by C-FSW and RC-FSW, respectively. Although similar welding parameters were adopted, the two welded joints experienced different cooling rates. It was found that an annealing twin with few dislocations can be detected in the SZ of the C-FSW joint (Fig. 4a). However, as liquid $\mathrm{N}_{2}$ cooling was operated, massive dislocations were maintained in the SZ due to the reduced post-annealing effect (Fig. 4b). Unfortunately, it exhibited a reduced elongation (EI) compared to the C-FSW copper.
During the FSW, the SZ experienced a severe deformation similar to hot forging and torsion. The material flow rate was lower than the probe rotation rate because there was a certain level of rotation lagging effect [22]. Chang et al. [22] provide a method to calculate the strain rate during the FSW process using Eq. (2):

$\dot{\varepsilon}=\frac{R_{\mathrm{m}} \cdot 2 \pi r_{\mathrm{e}}}{L_{\mathrm{e}}}$,

where $R_{\mathrm{m}}$ is about half of the rotation rate, and $r_{\mathrm{e}}$ and $L_{\mathrm{e}}$ are the effective radius and depth, respectively, of the SZ. The effective radius, which can represent the average radius for the SZ, $r_{\mathrm{e}}$, and $L_{\mathrm{e}}$, is assumed to be equal to about 0.78 of the observed SZ boundary radius and depth. In this study, all the observed SZs exhibited similar shapes, and therefore, we approximately defined half of the central line of the SZ in TD and ND as $r$ and $L$, respectively. Figure 5 provides the calculated strain rates and measured peak temperatures under different welding conditions. During the FSW process, the strain rate and the temperature increased with the increase in the rotation rate. The strain rates and peak temperatures during the FSW process were clearly much higher than those of the ECAP [19, 20, 23], rolling [24], and drawing processed $\mathrm{Cu}$ [25] due to the high-speed rotation tool. The activation energy $Q$ for copper lattice diffusion is about $72.5 \mathrm{~kJ} / \mathrm{mol}$ [26]. According to the strain rates and peak temperatures shown in Fig. 5, the $Z$ parameter can be calculated 

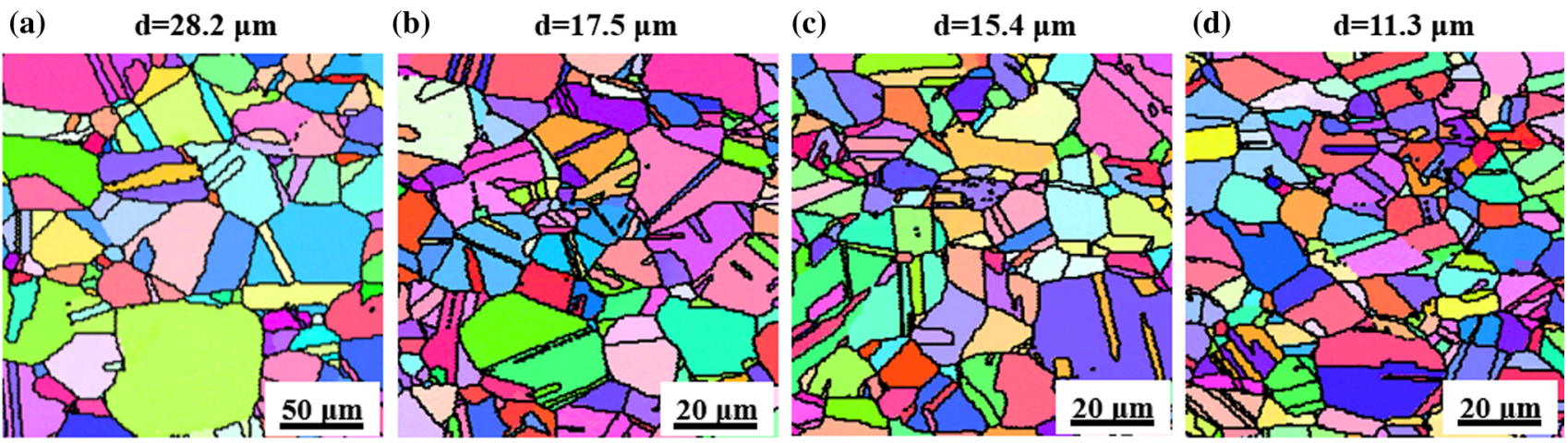

(e)

(f)

$\mathrm{d}=5.2 \mu \mathrm{m}$

(g)

$\mathrm{d}=4.1 \mu \mathrm{m}$

(h)

$\mathrm{d}=\mathbf{1 . 7} \mu \mathrm{m}$
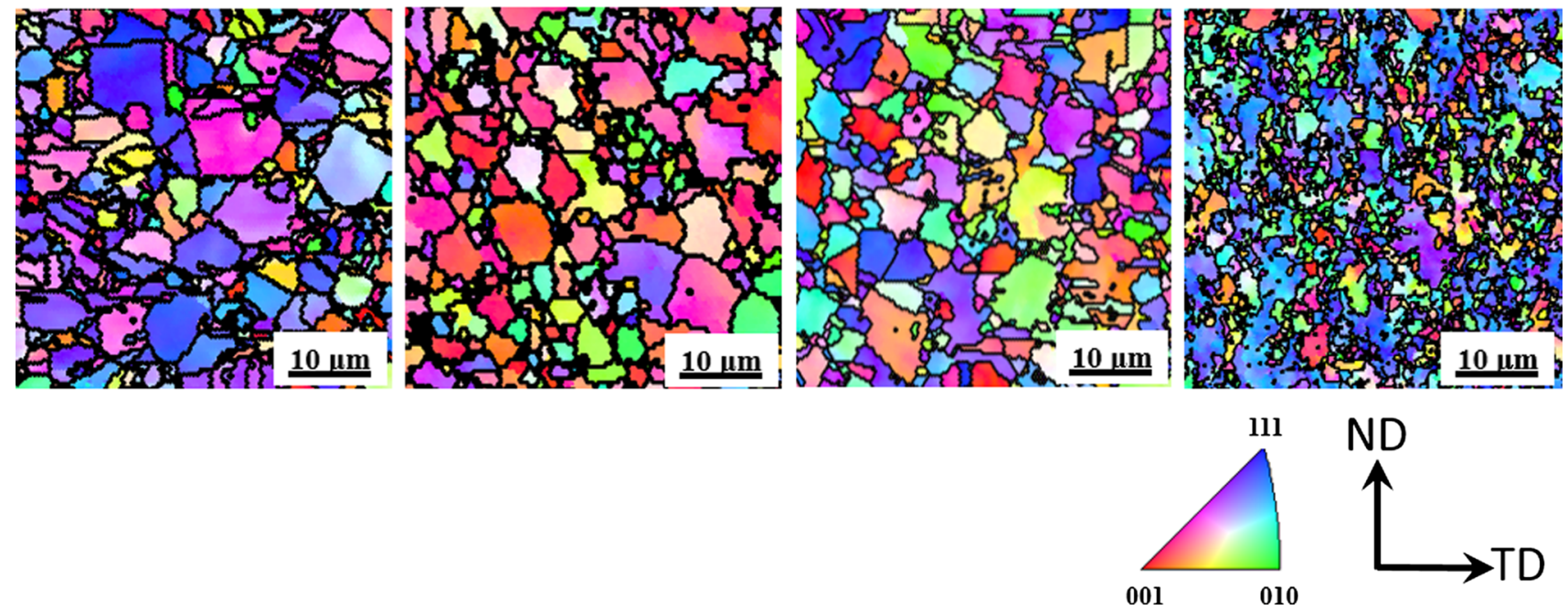

Fig. 2 Inverse pole figure (IPF) maps of a the BM, and the SZ centers of the b $1 \#, \mathbf{c} 2 \#, \mathbf{d} 3 \#, \mathbf{e} 4 \#, \mathbf{f} 5 \#, \mathbf{g}$ 6\#, $\mathbf{h}$ 7\# joints, respectively
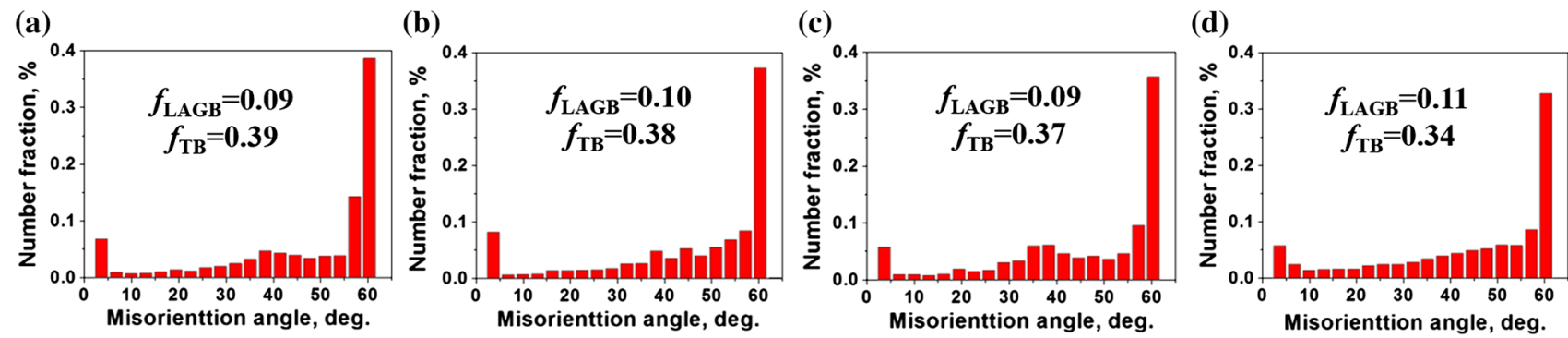

(e)

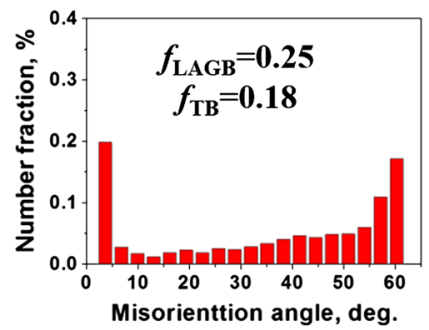

(f)

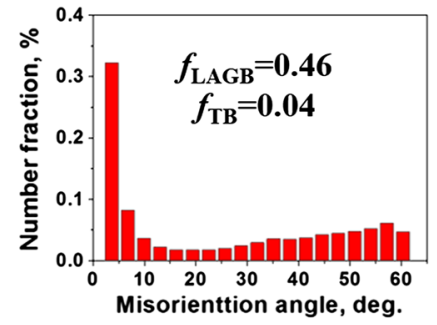

(g)

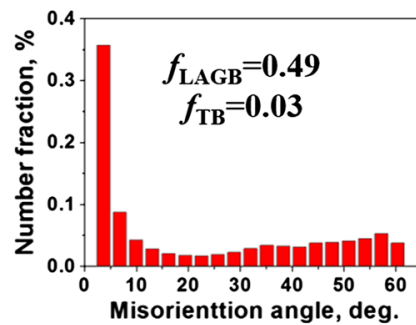

(h)

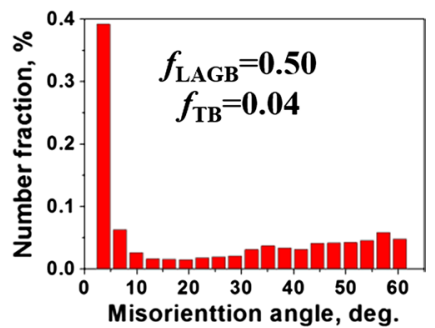

Fig. 3 Misorientation angle distribution of a the BM, and the SZ centers of the b $1 \#, \mathbf{c} 2 \#, \mathbf{d} 3 \#$, e 4\#, f 5\#, $\mathbf{g}$ 6\#, $\mathbf{h}$ 7\# joints, respectively 
Table 3 Vickers hardness and tensile properties of the BM and SZs obtained by different welding conditions

\begin{tabular}{lclll}
\hline & Hardness (Hv) & UTS (MPa) & YS (MPa) & EI (\%) \\
\hline BM & 63 & 215 & 120 & 58 \\
$1 \#$ & 71 & 250 & 145 & 34 \\
$2 \#$ & 76 & 253 & 148 & 33 \\
$3 \#$ & 83 & 258 & 154 & 33 \\
$4 \#$ & 91 & 252 & 178 & 30 \\
$5 \#$ & 97 & 260 & 184 & 30 \\
$6 \#$ & 110 & 268 & 212 & 29 \\
$7 \#$ & 118 & 282 & 220 & 27 \\
\hline
\end{tabular}
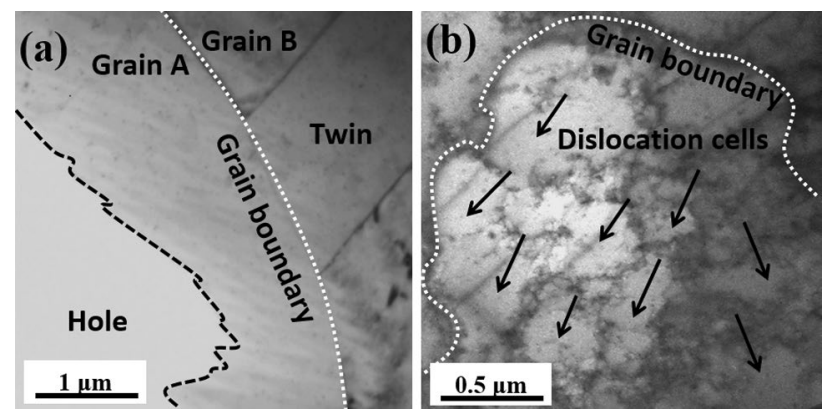

Fig. 4 Bright field TEM images of the SZ obtained by a C-FSW (1\#), b RC-FSW (7\#)

using Eq. (1). Figure 6 shows the relationship between the calculated $Z$ parameter and the average grain size $(d)$ in the SZ obtained by both C-FSW and RC-FSW. The plots exhibit a linear relationship that can be expressed by the following equations, respectively:

$\ln d=11.21-0.53 \ln Z$,

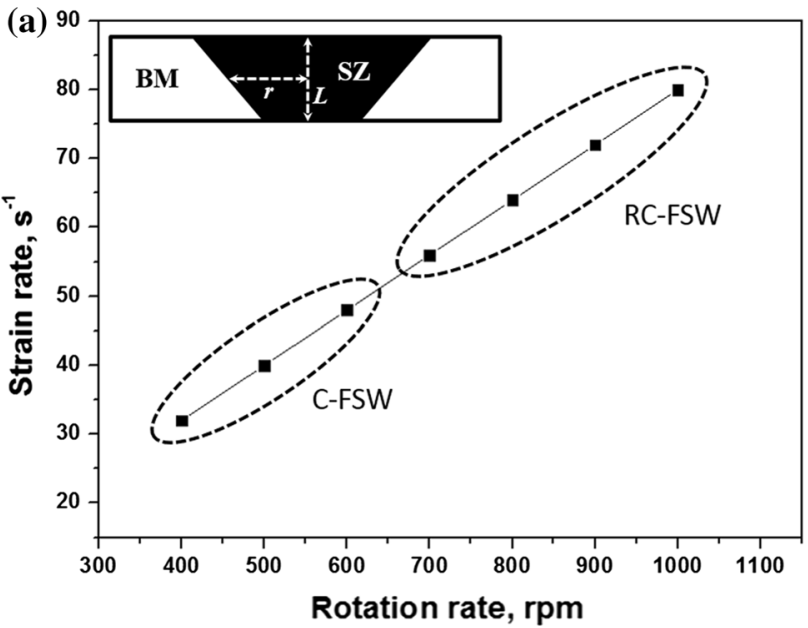

$\ln d=29.65-1.72 \ln Z$.

Clearly, the $Z$ parameter exhibited a narrower range of 15-17 $\mathrm{s}^{-1}$. Regardless of whether the liquid $\mathrm{N}_{2}$ cooling was adopted, the grain size significantly decreased with the increase in the $Z$ parameter. Chang et al. [23] also found such a relationship between the grain size and the $Z$ parameter during the FSP of the AZ31 magnesium alloy, and the $Z$ parameter varied in a very narrow range from 27 to $30 \mathrm{~s}^{-1}$. Jata et al. [27] also reported that the $Z$ parameter changed from 31 to $35 \mathrm{~s}^{-1}$ during the FSW of an Al-Li alloy. This is because, during the FSW, the strain rate and deformation temperature exhibit the same variation tendency that is dependent of the tool rotating rate. Moreover, as the liquid $\mathrm{N}_{2}$ cooling was operated, even with a very similar $Z$ parameter profile, the SZ showed a very different grain size; the grain coarsening caused by the annealing effect was efficiently controlled using liquid $\mathrm{N}_{2}$ cooling. Recently, Liu et al. [28] evaluated the strain rate during the FSW of Cu by measuring the distortion of the marker material $\mathrm{Cu}-40 \mathrm{Zn}$ foil. Based on their results, the average strain rate was calculated as $20.8 \mathrm{~s}^{-1}$, which is similar to our result of $15-17 \mathrm{~s}^{-1}$. Comparing the experimental results with the calculated results, it is believed that the empirical formula provided in Eq. (2) is still appropriate.

For metallic materials, the YS $\left(\sigma_{0.2}\right)$ is strongly dependent on grain size $(d)$, as can be expressed with the Hall-Petch equation [29-31]:

$\sigma_{0.2}=\sigma_{0}+k_{\mathrm{y}} d^{-1 / 2}$

where $\sigma_{0}$ is the friction stress and $k_{\mathrm{y}}$ is a positive constant. This relationship demonstrates that YS increases with decrease in grain size. In the present study, the Hall-Petch

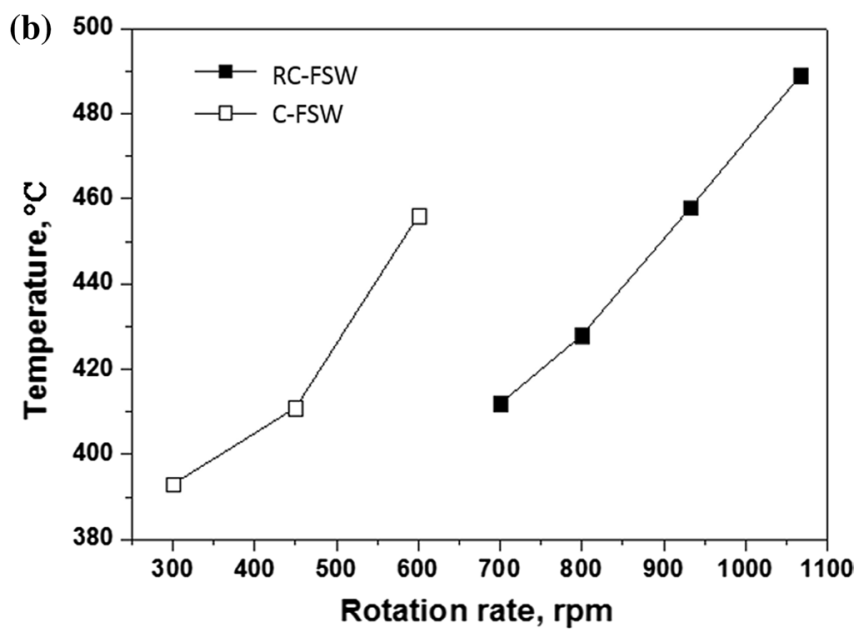

Fig. 5 Variations of $\mathbf{a}$ the strain rate, $\mathbf{b}$ the peak temperature under different welding conditions 


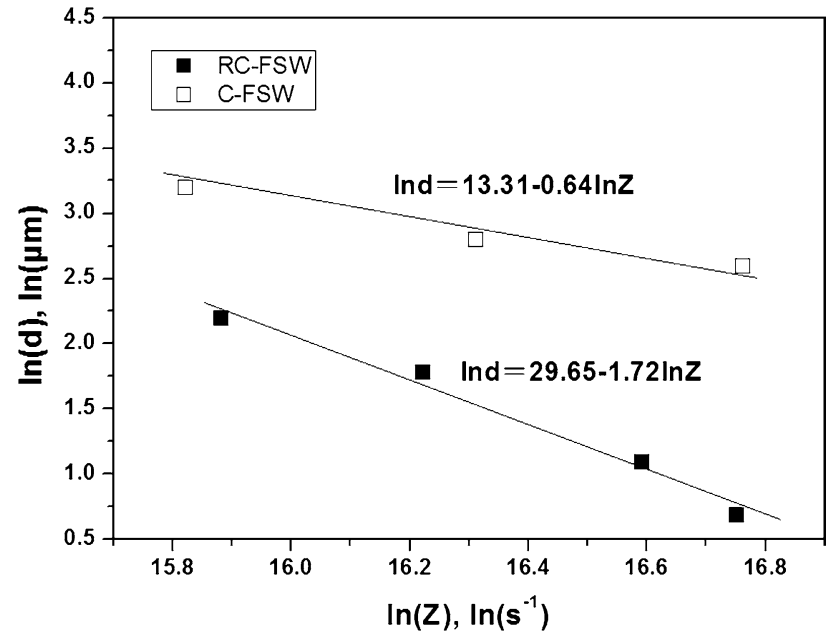

Fig. 6 Relationship between the grain size of the $\mathrm{SZ}$ and $Z$ parameter obtained under different welding conditions

equations obtained by C-FSW and RC-FSW can be evaluated as

$\sigma_{0.2}=117.5+112.5 d^{-1 / 2}$

and

$\sigma_{0.2}=138.1+119.0 d^{-1 / 2}$

respectively, and are also plotted in Fig. 7.

Clearly, if the post-annealing effect was reduced using liquid $\mathrm{N}_{2}$ cooling, the intercept and the slope of the Hall-Petch line changed due to the existence of the LAGB, which is created by dislocations. Similarly, Fujii et al. [32] evaluated the FSW of pure titanium by using a low heat input welding condition and also found that the Hall-Petch line

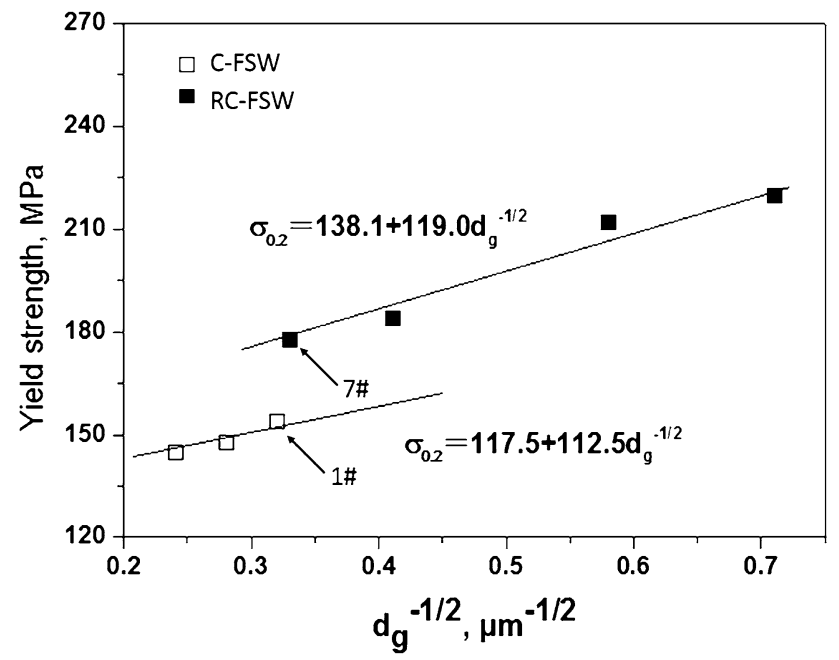

Fig. 7 Relationship between the grain size and the YS of the SZ obtained under different welding conditions changed due to the high dislocation density in the SZ caused by incomplete recovery and recrystallization.

Because this study aims to establish a relationship between the YS and the $Z$ parameter, the substitutions of Eqs. (3) into (6), and Eqs. (4) into (7) yield

$\sigma_{0.2}=117.5+1.7 \times 10^{-3} \cdot Z^{0.53}$,

and

$\sigma_{0.2}=138.1+4.3 \times 10^{-5} \cdot Z^{1.72}$,

respectively.

From Eqs. (8) and (9), the relationship between the YS and the $Z$ parameter can be concluded as

$\sigma_{0.2}=\sigma_{0}+k Z^{n}$,

where $k$ and $n$ are the constants dependent on the cooling rate during the post-welding period. It can be seen that the values of $k$ and $n$ are different under the different conditions of C-FSW and RC-FSW. According to Eqs. (8) and (9), the calculated relationship between the YS and the $Z$ parameter is plotted in Fig. 8, from which two important results can be observed. First, the YS profile of the SZ increased with the increase in the $Z$ parameter. In particular, when the $Z$ parameter ranged from 15 to $17 \mathrm{~s}^{-1}$ (the FSW process in this study), the YS increased significantly. Huang et al. provided a comprehensive evaluation of the process-structure-property linkage of FSW aluminum alloy via numerical simulation and particle experiments [33-35]. They also found that reducing the welding temperature and increasing the strain rate, i.e., increasing the $Z$ value, could help to obtain significant grain refinement and improve the yield strength. Second, with a similar $Z$ profile, the YS of the SZ obtained using liquid $\mathrm{N}_{2}$ cooling is much higher than that of the SZ obtained by air cooling. Such strength differences originated from the presence of the large number fraction of

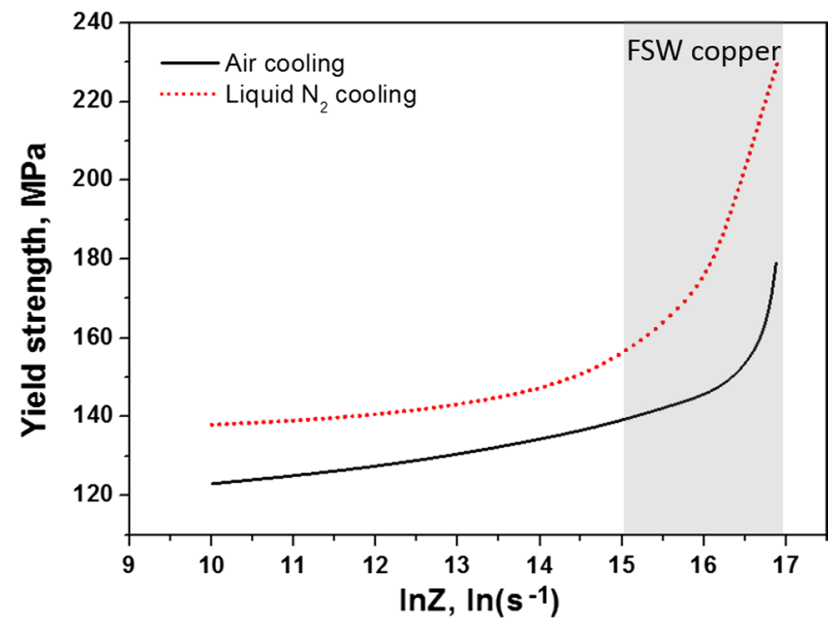

Fig. 8 Variations of the measured YS with $Z$ parameter 


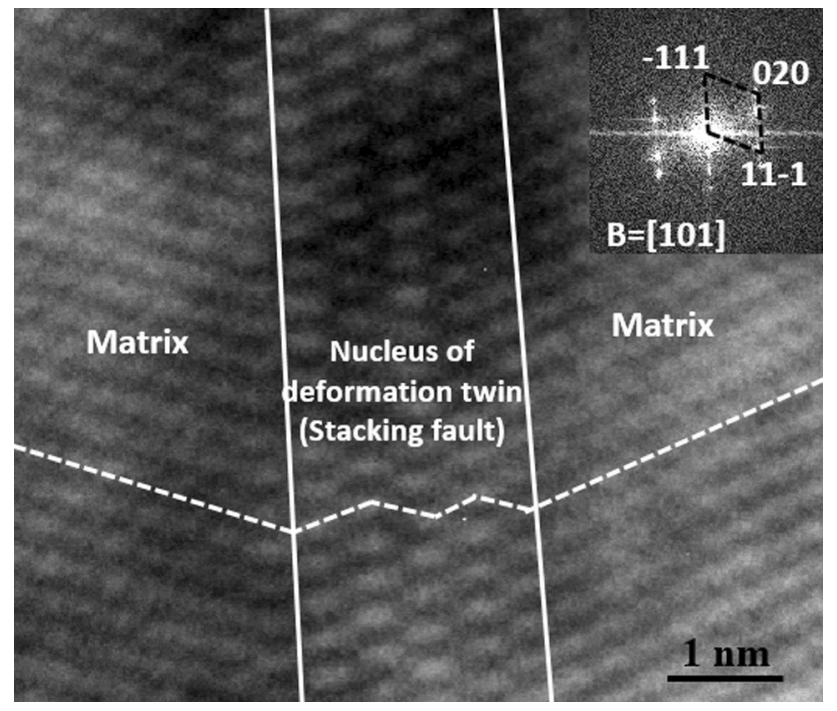

Fig. 9 High-resolution TEM image with selected-area election diffraction of the stacking fault in the tensile-tested SZ obtained by RCFSW (7\#)

the LAGB in the SZ, as shown in Fig. 2. It means that the cooling rate is an important factor that cannot be ignored when analyzing the relationship between YS and $Z$ parameter. Moreover, it can be also concluded that the FSW copper samples that underwent liquid $\mathrm{N}_{2}$ cooling were strengthened not only by the significant grain refinement, but also by the presence of the LAGB which was composed by dislocation cell and tangle. Similarly, Li et al. [18] reported that during the low temperature deformation of copper, a YS difference will occur at the same $Z$ parameter value due to the appearance of the substructures in the grains. An et al. [36] conducted hot compression deformation on a $\mathrm{Fe}-3 \% \mathrm{Si}$ alloy within a temperature range of 1073-1473 K and strain rate range of $0.01-5 \mathrm{~s}^{-1}$. A quantitative description of the subgrain size and boundary misorientation has been set up as a function of the $Z$ parameter. It was found that as the $Z$ parameter decreased, the subgrain size and misorientation angle increased. Dynamic recovery and partial dynamic recrystallization were the dominant softening mechanisms. As summarized in Table 3, it was also found that the uniform elongation was not significantly reduced for the RC-FSW copper. According to previous studies, there is still enough driving force to further form deformation twins in the tensile process [37, 38]. A toughening mechanism related to dislocation-deformation twins plays an important role in tensile deformation $[39,40]$. Therefore, in addition, the thickness of the twins in RC-FSW pure copper is much smaller than that of annealed twins, which is usually less than $10 \mathrm{~nm}$ (Fig. 9). Similar to the coarsened annealed twins, a large number of deformed twins that originate from stacking fault can hinder the dislocation movement and decompose dislocations. In other words, deformed twins provide more space to accommodate dislocations, thus improving ductility and the work hardening rate. This not only helps to adjust plastic deformation, but also improves the strain hardening rate via the twininduced plasticity effect, thus further improving ductility.

\section{Conclusions}

In this study, the FSW of copper was operated in conditions of air cooling and liquid $\mathrm{N}_{2}$ cooling to investigate how the $Z$ parameter affects the microstructure and mechanical properties of the SZ. The following conclusions were obtained.

(1) Using liquid $\mathrm{N}_{2}$ cooling, the SZ exhibited an ultrafine grain structure with a high dislocation density due to the reduced post-annealing effect.

(2) A higher rotation rate resulted in a higher strain rate and higher peak temperatures in the SZ. These two factors were primarily responsible for controlling the $Z$ parameter. Regardless of whether the liquid $\mathrm{N}_{2}$ cooling was performed, the grain size decreased with the increase in the $Z$ parameter.

(3) Under the different conditions of air cooling and liquid $\mathrm{N}_{2}$ cooling, two different Hall-Petch relationships with different intercepts and slopes were obtained. The relationship between the YS and the $Z$ parameter was established as $\sigma_{0.2}=\sigma_{0}+k Z^{n}$.

Acknowledgements This research was financial supported by the National Natural Science Foundation of China (No. 51805145), the Fundamental Research Funds for the Central Universities of China (No. 2018B22514), and the Natural Science Foundation of Jiangsu Province (No. BK20160284).

\section{References}

[1] K. Nakata, Weld. Int. 19, 929-933 (2005)

[2] H. Khodaverdizadeh, A. Mahmoudi, A. Heidarzadeh, E. Nazari, Mater. Des. 35, 330-334 (2012)

[3] W.B. Lee, S.B. Jung, Mater. Lett. 58, 1041-1046 (2004)

[4] Y.F. Wang, J. An, K. Yin, M.S. Wang, Y.S. Li, C.X. Huang, Acta Metall. Sin. (Engl. Lett.) 31, 878-886 (2018)

[5] S. Emami, T. Saeid. Acta Metall. Sin. (Engl. Lett.) 28 (2015) 766-771

[6] R.S. Mishra, Z.Y. Ma, Mater. Sci. Eng. R 50, 1-78 (2005)

[7] G.M. Xie, Z.Y. Ma, L. Geng, Scr. Mater. 57, 73-76 (2007)

[8] H.J. Liu, J.J. Shen, Y.X. Huang, L.Y. Kuang, C. Liu, C. Li, Sci. Technol. Weld. Join. 14, 577-583 (2009)

[9] Y.F. Sun, H. Fujii, Mater. Sci. Eng. A 527, 6879-6886 (2010)

[10] P. Xue, B.L. Xiao, Q. Zhan, Z.Y. Ma, Scr. Mater. 64, 1051-1054 (2011)

[11] N. Xu, R. Ueji, H. Fujii, J. Mater. Process. Technol. 232, 90-99 (2016) 
[12] N. Xu, R. Ueji, Y. Morisada, H. Fujii, Mater. Des. 56, 20-25 (2014)

[13] N. Xu, R. Ueji, H. Fujii, Mater. Sci. Eng. A 610, 132-138 (2014)

[14] C. Zener, J.H. Hollomon, J. Appl. Phys. 15, 22-32 (1944)

[15] N. Yan, H.S. Di, H.Q. Huang, R.D.K. Misra, Y.G. Deng, Acta Metall. Sin. (Engl. Lett.) 32, 1021-1031 (2019)

[16] E.X. Pu, W.J. Zheng, J.Z. Xiang, Z.G. Song, H. Feng, Y.L. Zhu, Acta Metall. Sin. (Engl. Lett.) 27, 313-323 (2014)

[17] C. Wu, S. Han, Acta Metall. Sin. (Engl. Lett.) 31, 963-974 (2018)

[18] Y.S. Li, Y. Zhang, N.R. Tao, K. Lu, Acta Mater. 57, 761-772 (2009)

[19] Y.M. Wang, T. Jiao, E. Ma, Mater. Trans. 44, 1926-1934 (2003)

[20] J. Gubicza, N.H. Nam, L. Balogh, R.J. Hellmig, V.V. Stolyarov, Y. Estrin, T. Ungára, J. Alloys Compd. 378, 248-252 (2004)

[21] N. Xu, Q.N. Song, Y.F. Bao, Mater. Sci. Eng. A 726, 169-178 (2018)

[22] C.I. Chang, C.J. Lee, J.C. Huang, Scr. Mater. 51, 509-514 (2004)

[23] F.D. Torre, R. Lapovok, J. Sandlin, P.F. Thomson, C.H.J. Davies, Acta Mater. 52, 4819-4832 (2004)

[24] Y.M. Wang, M.W. Chen, H.W. Sheng, E. Ma, J. Mater. Res. 17, 3004-3007 (2002)

[25] K. Han, R.P. Walsh, A. Ishmaku, V. Toplosky, L. Brandao, J.D. Embury, Philos. Mag. 84, 3705-3716 (2004)

[26] B. Zhang, V.P.W. Shim, Acta Mater. 58, 6810-6827 (2010)

[27] K.V. Jata, S.L. Semiatin, Scr. Mater. 43, 743-749 (2000)
[28] X.C. Liu, Y.F. Sun, T. Nagira, K. Ushioda, H. Fujii, Sci. Technol. Weld. Join. 24, 352-359 (2019)

[29] Y.S. Sato, M. Urata, H. Kokawa, K. Ikeda, Mater. Sci. Eng. A 354, 298-305 (2003)

[30] H. Hasegawa, S. Komura, A. Utsunomiya, Z. Horita, M. Furukawa, M. Nemoto, T.G. Langdon, Mater. Sci. Eng. A 265, 188 196 (1999)

[31] N. Xu, J. Shen, W.D. Xie, L.D. Wang, D. Wang, D. Min, Mater. Charact. 61, 713-719 (2010)

[32] H. Fujii, Y.F. Sun, H. Kato, K. Nakata, Mater. Sci. Eng. A 527, 3386-3391 (2010)

[33] Y.X. Huang, Y.M. Xie, X.C. Meng, J.C. Li, L. Zhou, J. Mater. Sci. Technol. 35, 1261-1269 (2019)

[34] Y.X. Huang, Y.M. Xie, X.C. Meng, J.C. Li, Mater. Sci. Eng. A 740-741, 211-217 (2019)

[35] Y.X. Huang, Y.M. Xie, X.C. Meng, Z.L. Lv, J. Cao, J. Mater. Process. Technol. 252, 233-241 (2018)

[36] F.H. An, Y.H. Sha, F. Zhang, L. Zuo, Acta Metall. Sin. (Engl. Lett.) 24, 1-8 (2011)

[37] X.H. An, S.D. Wu, Z.F. Zhang, R.B. Figueiredo, N. Gao, T.G. Langdon, Scr. Mater. 66, 227-230 (2012)

[38] H.K.D.H. Bhadeshia, Scr. Mater. 66, 955 (2012)

[39] K. Lu, L. Lu, S. Suresh, Science 324, 349-352 (2009)

[40] Y. Zhang, N.R. Tao, K. Lu, Acta Mater. 59, 6048-6058 (2011) 